\title{
Traduire
}

Revue française de la traduction

$240 \mid 2019$

Quand la politique s'en mêle

\section{Lu pour vous : Diagonales de la communication interculturelle, de Martine Abadallah-Pretceille et Louis Porcher}

El Mehdi Soltani

\section{CpenEdition}

Journals

Édition électronique

URL : http://journals.openedition.org/traduire/1751

DOI : 10.4000/traduire. 1751

ISSN : 2272-9992

Éditeur

Société française des traducteurs

Édition imprimée

Date de publication : 20 juin 2019

Pagination : 122-124

ISSN : 0395-773X

\section{Référence électronique}

El Mehdi Soltani, «Lu pour vous : Diagonales de la communication interculturelle, de Martine AbadallahPretceille et Louis Porcher», Traduire [En ligne], 240 | 2019, mis en ligne le 20 juin 2019, consulté le 24 septembre 2020. URL : http://journals.openedition.org/traduire/1751 ; DOI : https://doi.org/10.4000/ traduire. 1751 


\section{Lu pour vous}

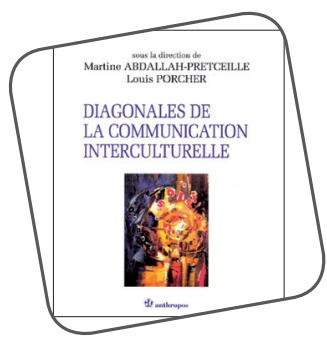

\section{Diagonales de la communication interculturelle, de Martine Abadallah- Pretceille et Louis Porcher}

El Mehdi Soltani

Martine Abdallah-Pretceille est professeur des universités (Paris VIII, Paris III Sorbonne). Elle est l'auteure de nombreux ouvrages et articles sur la diversité culturelle et l'interculturalité, l'éducation et la communication interculturelle. Louis Porcher (19402014), professeur émérite à la Sorbonne, sociologue et écrivain français, a été responsable du français langue étrangère (FLE) au ministère de l'Éducation nationale de 1981 à 1984. Il a terminé sa carrière comme professeur des universités à l'unité de formation et de recherche de didactique du FLE de l'université Sorbonne Nouvelle (Paris 3). Ses nombreuses publications ont pour thème principal l'enseignement du français (langue maternelle et étrangère) et des langues vivantes.

Dans leur ouvrage Diagonales de la communication interculturelle, Martine Abadallah-Pretceille et Lovis Porcher s'intéressent à une forme de communication ayant pour principe de base la modernité, marquée par une pluralité des formes de socialisation, de culture, d'éducation, de langage ou encore d'être au monde et aux autres. À l'heure où l'enjeu interculturel est prépondérant, ils abordent leur problématique selon trois aspects: la quotidienneté, la littérature et les médias. 
La partie consacrée à la quotidienneté développe des notions incontournables dans l'interculturel. Elle souligne notamment l'importance qu'il y a à connaître la culture de l'autre dans un contexte où la communication se résumerait à une bonne maîtrise des signes linguistiques et culturels, d'où les difficultés d'interprétation de faits culturels souvent relevées entre des groupes socioculturellement différents. Elle dépeint ensuite les expériences interculturelles d'étudiants américains nouvellement arrivés en France pour suivre des études dans des universités parisiennes, et insiste sur l'importance qu'il y a à décrire les conduites et les comportements en contexte, mais aussi à analyser les actions pratiques et le programme culturel qui leur sont proposés. L'idée est alors soulevée que toute personne plongée dans un nouvel univers culturel est confrontée à des modes d'interprétation différents et déstabilisants, sans cependant percevoir d'emblée le décalage entre les deux systèmes culturels et à s'en tenir à sa propre grille d'analyse pour interpréter le message d'autrui ou la situation observée. Est enfin proposée l'analyse d'un contexte d'échange universitaire, propice à la rencontre de plusieurs groupes d'étudiants ayant pour langue véhiculaire une autre langue que leur langue maternelle: celle qu'ils sont en train d'apprendre. La communication leur permet d'interagir, d'échanger des informations et des messages qui les plongent dans une situation de réciprocité appelée "interculturelle», dans laquelle interviennent plusieurs éléments et critères: signes verbaux, non verbaux et paraverbaux, transgressions du code linguistique, stratégies de facilitation à travers l'usage de la langue maternelle, références culturelles partagées et non partagées, aspects ludiques de la transgression du code linguistique, contacts physiques, etc.

La deuxième partie de l'ouvrage fait le point sur la littérature et son rôle dans la communication interculturelle. Plusieurs écrivains et critiques littéraires ont abordé la problématique interculturelle dans leurs écrits, tout particulièrement à travers des récits de voyage relatant des rencontres entre individus aux appartenances culturelles variées. Elle est illustrée par une étude analytique et comparative d'Un amour de Swann de Marcel Proust et de Voyages au Canada de Jacques Cartier, et aborde la méconnaissance de la langue et des codes culturels susceptible de générer des malentendus, voire un dysfonctionnement interculturel. D'autres exemples, cette fois tirés de la littérature 
chilienne, s'intéressent à la découverte de soi, parfois bouleversante dans une situation de communication interculturelle. La signification des éléments culturels précis varie alors selon le contexte situationnel et la personnalité de l'individu qui en fait usage. Est également évoquée la réflexion d'Octavio Paz au sujet de la double dimension subjective et collective de la production culturelle, qui s'appuie sur l'expérience de l'altérité et le rapport entre soi et autrui, entre l'individu et la société, entre le passé et le présent, entre la quête identitaire et la culture nationale.

Enfin, la troisième partie de l'ouvrage s'intéresse au regard des hommes, à l'humanité et au spectacle dont les médias se font le relais dans leur diversité linguistique et culturelle. Elle souligne que le travail culturel des médias ne se limite pas à la multiplication des titres, des chaînes et des stations, aux messages ou à l'évolution technologique, mais touche aussi la position interculturelle et la transmission du message et sa compréhension par des groupes dont les cultures ne sont pas forcément les mêmes. Certains médias, quand ils en prennent conscience, intègrent la didactique des langues à leurs missions - comme en témoigne le sous-titrage des films et des émissions télévisées. En guise de conclusion, l'ouvrage invite à faire se télescoper les médias et l'interculturel, avec la transition de la transmission analogique des faits culturels à la transmission numérique d'images et de sons emblématiques du quotidien et des éléments culturels d'une société.

soltani.mehdi02@gmail.com

Martine Abadallah-Pretceille et Louis Porcher, Diagonales de la communication interculturelle, Economica/Anthropos éditions, 1999. 